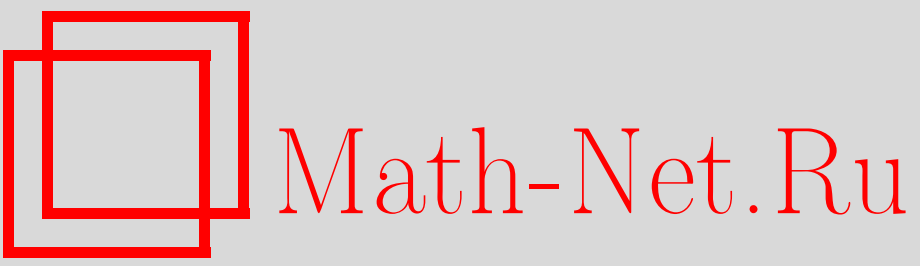

M. Magdziarz, A note on Maruyama's mixing theorem, Теория вероятн. и ее примен., 2009, том 54, выпуск 2, 407-409

DOI: https://doi.org/10.4213/tvp2720

Использование Общероссийского математического портала Math-Net.Ru подразумевает, что вы прочитали и согласны с пользовательским соглашением

http://www.mathnet.ru/rus/agreement

Параметры загрузки:

IP : 3.82 .47 .9

26 апреля 2023 г., 16:17:01 


\section{A NOTE ON MARUYAMA'S MIXING THEOREM}

Г. Маруяма в фундаментальной статье [3] (1970, теорема 6) привел необходимые и достаточные условия для того, чтобы стационарный безгранично делимый процесс был процессом с перемешиванием. Мы показываем, что последнее условие в теореме Маруямы следует из предпоследнего. Этот результат позволяет получить существенно более простую версию теоремы Маруямы.

Ключевые слова и фразы: безгранично делимые процессы, стационарные процессы с перемешиванием.

Let $\left(X_{t}\right)_{t \in \mathbf{R}}$ be an infinitely divisible (i.d.) stochastic process, i.e., a process whose all finite dimensional distributions are i.d. Recall that a probability distribution $\mu$ on $\mathbf{R}^{d}$ is i.d. if its characteristic function has the form (Lévy-Khinchine formula)

$\mathscr{F}_{\mu}(z)=\exp \left\{-i(a, z)-\frac{1}{2} G(z)-\int_{\mathbf{R}^{d}}\left(1-e^{i(x, z)}+i\langle x, z\rangle \mathbf{1}_{\{|x|<1\}}\right) Q(d x)\right\}, \quad z \in \mathbf{R}^{d}$.

Here $a \in \mathbf{R}^{d}, G$ is a positive semi-definite quadratic form on $\mathbf{R}^{d}$ called the Gaussian coefficient, and $Q$ is the so-called Lévy measure, i.e., a measure on $\mathbf{R}^{d} \backslash\{0\}$ satisfying $\int\left(1 \wedge|x|^{2}\right) Q(d x)<\infty$.

A stationary i.d. process $\left(X_{t}\right)_{t \in \mathbf{R}}$ defined on the canonical space $\left(\mathbf{R}^{\mathbf{R}}, \mathscr{F}, \mathbf{P}\right)$ is said to be mixing if

$$
\mathbf{P}\left(A \cap S^{t} B\right) \longrightarrow \mathbf{P}(A) \mathbf{P}(B)
$$

as $t \rightarrow \infty$ for every $A, B \in \mathscr{F}$, where $\left(S^{t}\right)$ is a group of shift transformations on $\mathbf{R}^{\mathbf{R}}$.

The description of the mixing property for stationary i.d. processes in terms of their Lévy characteristics dates back to the fundamental paper by Maruyama [3] (Theorema 6). He proved that an i.d. stationary process $\left(X_{t}\right)_{t \in \mathbf{R}}$ is mixing if and only if

(C1) the covariance function $r(t)$ of its Gaussian part converges to 0 as $t \rightarrow \infty$,

(C2) $\lim _{t \rightarrow \infty} Q_{0 t}(|x y|>\delta)=0$ for every $\delta>0$, and

(C3) $\lim _{t \rightarrow \infty} \int_{0<x^{2}+y^{2} \leqslant 1} x y Q_{0 t}(d x, d y)=0$, where $Q_{0 t}$ is the Lévy measure of $\left(X_{0}, X_{t}\right)$.

The above result was crucial for further scientific research on the subject of ergodic properties of stochastic processes, and has been extensively exploited by many authors (see, e.g., [1], [2], [4]). In what follows, we show that condition (C2) implies (C3), and therefore the necessary and sufficient conditions for an i.d. process to be mixing can be reduced only to $(\mathrm{C} 1)$ and $(\mathrm{C} 2)$. As a consequence, the proofs and methods used in the above-cited references, which based on Maruyama's theorem, can be essentially simplified.

Lemma 1. Assume that $\lim _{t \rightarrow \infty} Q_{0 t}(|x y|>\delta)=0$ for every $\delta>0$. Then, we get

$$
\lim _{t \rightarrow \infty} \int_{0<x^{2}+y^{2} \leqslant 1} x y Q_{0 t}(d x, d y)=0 .
$$

$\mathrm{P}$ r o o f. First, let us notice that the assumption in the lemma implies that

$$
\lim _{t \rightarrow \infty} Q_{0 t}(|x| \wedge|y|>l)=0 \quad \text { for every } l>0,
$$

where $a \wedge b=\min \{a, b\}$. Indeed, putting $\delta=l^{2}$, we get

$$
Q_{0 t}(|x| \wedge|y|>l) \leqslant Q_{0 t}(|x y|>\delta) \longrightarrow 0 \quad \text { as } t \rightarrow \infty .
$$

* Institute of Mathematics and Computer Science, Wroclaw University of Technology, 50-370 Wroclaw, Poland; e-mail: marcin.magdziarz@pwr.wroc.pl 

obtain

Now, fix $\varepsilon>0$, put $B_{\delta}=\left\{x^{2}+y^{2} \leqslant \delta^{2}\right\}$ and $R_{\delta}=\left\{\delta^{2}<x^{2}+y^{2} \leqslant 1\right\}$. Then, we

$$
\int_{0<x^{2}+y^{2} \leqslant 1}|x y| Q_{0 t}(d x, d y)=\int_{B_{\delta}}|x y| Q_{0 t}(d x, d y)+\int_{R_{\delta}}|x y| Q_{o t}(d x, d y)=: I_{1}+I_{2} .
$$

We will estimate the terms $I_{1}$ and $I_{2}$ separately.

Taking advantage of stationarity of $Q_{0 t}$, we get for the first term

$$
\begin{aligned}
I_{1} & \leqslant \frac{1}{2} \int_{B_{\delta}} x^{2} Q_{0 t}(d x, d y)+\frac{1}{2} \int_{B_{\delta}} y^{2} Q_{0 t}(d x, d y) \\
& \leqslant \frac{1}{2} \int_{\left\{x^{2} \leqslant \delta^{2}\right\}} x^{2} Q_{0 t}(d x, d y)+\frac{1}{2} \int_{\left\{y^{2} \leqslant \delta^{2}\right\}} y^{2} Q_{0 t}(d x, d y)=\int_{|x| \leqslant \delta} x^{2} Q_{0}(d x) .
\end{aligned}
$$

Here $Q_{0}$ is the Lévy measure of $X_{0}$. Thus, for some appropriately small $\delta_{0}$ we have

$$
I_{1}=\int_{B_{\delta_{0}}}|x y| Q_{0 t}(d x, d y) \leqslant \frac{\varepsilon}{2} .
$$

For the second term, put $l_{0}=\min \left\{\delta_{0} / 2, \varepsilon /(8 q)\right\}$, with $q=Q_{0}\left(|x|>\delta_{0} / 2\right)<\infty$. Then, for $C=R_{\delta_{0}} \cap\left\{|x| \wedge|y|>l_{0}\right\}$ we obtain

$$
\begin{aligned}
I_{2} & =\int_{C}|x y| Q_{0 t}(d x, d y)+\int_{R_{\delta_{0}} \backslash C}|x y| Q_{0 t}(d x, d y) \leqslant Q_{0 t}(C)+\int_{R_{\delta_{0}} \backslash C} \frac{\varepsilon}{8 q} Q_{0 t}(d x, d y) \\
& \leqslant Q_{0 t}\left(|x| \wedge|y|>l_{0}\right)+\frac{\varepsilon}{8 q} Q_{0 t}\left(R_{\delta_{0}} \backslash C\right) \\
& \leqslant Q_{0 t}\left(|x| \wedge|y|>l_{0}\right)+\frac{\varepsilon}{8 q} Q_{0 t}\left(\left\{|x|>\frac{\delta_{0}}{2}\right\} \cup\left\{|y|>\frac{\delta_{0}}{2}\right\}\right) \\
& \leqslant Q_{0 t}\left(|x| \wedge|y|>l_{0}\right)+\frac{\varepsilon}{8 q} Q_{0 t}\left(|x|>\frac{\delta_{0}}{2}\right)+\frac{\varepsilon}{8 q} Q_{0 t}\left(|y|>\frac{\delta_{0}}{2}\right) \\
& =Q_{0 t}\left(|x| \wedge|y|>l_{0}\right)+\frac{\varepsilon}{4 q} Q_{0}\left(|x|>\frac{\delta_{0}}{2}\right)=Q_{0 t}\left(|x| \wedge|y|>l_{0}\right)+\frac{\varepsilon}{4} .
\end{aligned}
$$

Using (2), for $t$ large enough we have $Q_{0 t}\left(|x| \wedge|y|>l_{0}\right)<\varepsilon / 4$, and therefore

$$
I_{2}=\int_{R_{\delta_{0}}}|x y| Q_{0 t}(d x, d y)<\frac{\varepsilon}{2} .
$$

Finally, combining (3) and (4), and letting $\varepsilon \searrow 0$, we obtain the desired result.

The above result allows us to formulate the following simplified version of Maruyama's mixing theorem.

Theorem 1. An i.d. stationary process $\left(X_{t}\right)_{t \in \mathbf{R}}$ is mixing if and only if the following two conditions hold:

(C1) the covariance function $r(t)$ of its Gaussian part converges to 0 as $t \rightarrow \infty$, and

(C2) $\lim _{t \rightarrow \infty} Q_{0 t}(|x y|>\delta)=0$ for every $\delta>0$, where $Q_{0 t}$ is the Lévy measure of $\left(X_{0}, X_{t}\right)$.

P r o o f. Necessity follows directly from the Maruyama theorem. For sufficiency, let us notice that from Lemma 1 we see that condition (C2) implies (C3). Thus, the process must be mixing.

$\mathrm{R}$ e $\mathrm{m}$ a $\mathrm{rk}$. Condition $(\mathrm{C} 2)$ says that the Lévy measure $Q_{0 t}$ is asymptotically concentrated on the axes, which for an i.d. distribution is equivalent to the asymptotic independence of the Poissonian parts of $X_{0}$ and $X_{t}$. Therefore, conditions (C1) and (C2) yield the asymptotic independence of $X_{0}$ and $X_{t}$, which, in view of definition (1), is the natural interpretation of mixing property. 


\section{REFERENCES}

1. Gross A. Some mixing conditions for stationary symmetric stable stochastic processes. - Stochastic Process. Appl., 1994, v. 51, № 2, p. 277-295.

2. Janicki A., Weron A. Simulation and Chaotic Behavior of $\alpha$-Stable Stochastic Processes. New York: Dekker, 1994, 355 p.

3. Maruyama G. Infinitely divisible processes. - Теория вероятн. и ее примен., 1970, т. 15 , в. 1 , с. $3-23$.

4. Rosiński J., Żak T. Simple conditions for mixing of infinitely divisible processes. Stochastic Process. Appl., 1996, v. 61, № 2, p. 277-288.

Поступила в редакцию 16.X.2006

Исправленный вариант

03.XI.2008 